\title{
Small Cell Lung Cancer Complicated by Pulmonary Sarcoidosis
}

\author{
Hirokazu Tokuyasu ${ }^{1}$, Hiroki Izumi ${ }^{1}$, Natsuko Mukai ${ }^{1}$, Kenichi Takeda ${ }^{1}$, Yasuto Sakaguchi ${ }^{2}$, \\ Noritaka Isowa $^{2}$ and Eiji Shimizu ${ }^{3}$
}

\begin{abstract}
In July 2009, a 69-year-old man was admitted to our hospital because an abnormal chest shadow had been noted on medical examination. Chest radiography and computed tomography showed mediastinal and bilateral hilar lymphadenopathy. Bronchoalveolar lavage fluid (BALF) from the right $\mathrm{B}^{5}$ revealed an increased CD4/CD8 ratio. Histological examination of the biopsy specimens obtained from the tumor in the left upper bronchus revealed small cell lung cancer, whereas examination of the specimens obtained from the left $\mathrm{B}^{3}$ revealed noncaseating epithelioid cell granulomas containing giant cells, confirming the diagnosis of sarcoidosis. The patient underwent chemotherapy with carboplatin and etoposide without any steroids. After 4 courses of chemotherapy, bronchoscopic examination revealed that the tumor had shrunk, and the BALF CD4/CD8 ratio had decreased; further, no histological evidence of sarcoidosis was seen in specimens obtained from the left $\mathrm{B}^{3}$. Concomitant small cell lung cancer and sarcoidosis is rare. Interestingly, cancer chemotherapy might improve pulmonary sarcoidosis.
\end{abstract}

Key words: sarcoidosis, small cell lung cancer, chemotherapy

(Inter Med 49: 1997-2001, 2010)

(DOI: 10.2169/internalmedicine.49.3797)

\section{Introduction}

Small cell lung cancer is rarely associated with sarcoidosis. Here, we report the rare case of a patient who presented with bilateral hilar lymphadenopathy, as revealed by chest radiography, and who was diagnosed with pulmonary sarcoidosis and small cell lung cancer on the basis of the results of histological examinations. After 4 courses of chemotherapy with carboplatin and etoposide without any steroids, both small cell lung cancer and sarcoidosis were alleviated.

\section{Case Report}

In July 2009, a 69-year-old Japanese man was referred to our hospital for evaluation of a chest roentgenogram that showed bilateral hilar lymphadenopathy. He was a smoker ( 3 packs a day for 50 years). The findings of physical ex- amination were normal. Peripheral lymphadenopathy was not detected in the cervical, axillary, or inguinal region. The results of chest auscultation were normal.

His white blood cell count was $5.5 \times 10^{9} / \mathrm{L}$ with $56.0 \%$ neutrophils, $31.0 \%$ lymphocytes, $7.0 \%$ monocytes, and $6.0 \%$ eosinophils. The total protein level was $7.8 \mathrm{~g} / \mathrm{dL}$ with $55.3 \%$ albumin and $17.4 \%$ gamma globulin. Further, calcium and soluble interleukin-2 receptor (sIL-2R) levels were slightly elevated, i.e., $9.9 \mathrm{mg} / \mathrm{dL}$ (normal range, 8.2-9.8 $\mathrm{mg} / \mathrm{dL}$ ), and $594 \mathrm{U} / \mathrm{mL}$ (normal range, 127-582 U/mL), respectively. The serum angiotensin-converting enzyme (ACE) level was increased to $27.4 \mathrm{U} / \mathrm{L}$ (normal range, 8.3-21.4 U/L), whereas the lysozyme level was within the normal limit. The levels of pro-gastrin-releasing peptide (Pro-GRP) and neuronspecific enolase (NSE), which are markers for small cell lung cancer, were increased to $814 \mathrm{pg} / \mathrm{mL}$ (normal range, 0$46 \mathrm{pg} / \mathrm{mL}$ ) and $30 \mathrm{ng} / \mathrm{mL}$ (normal range, $0-10 \mathrm{ng} / \mathrm{mL}$ ), respectively. The results of pulmonary function tests were as

${ }^{1}$ Division of Respiratory Medicine, Matsue Red Cross Hospital, Matsue, ${ }^{2}$ Thoracic Surgery, Matsue Red Cross Hospital, Matsue and ${ }^{3}$ Division of Medical Oncology and Molecular Respirology, Department of Multidisciplinary Internal Medicine, Faculty of Medicine, Tottori University, Yonago

Received for publication April 12, 2010; Accepted for publication June 7, 2010

Correspondence to Dr. Hirokazu Tokuyasu, tokuun3200@yahoo.co.jp 


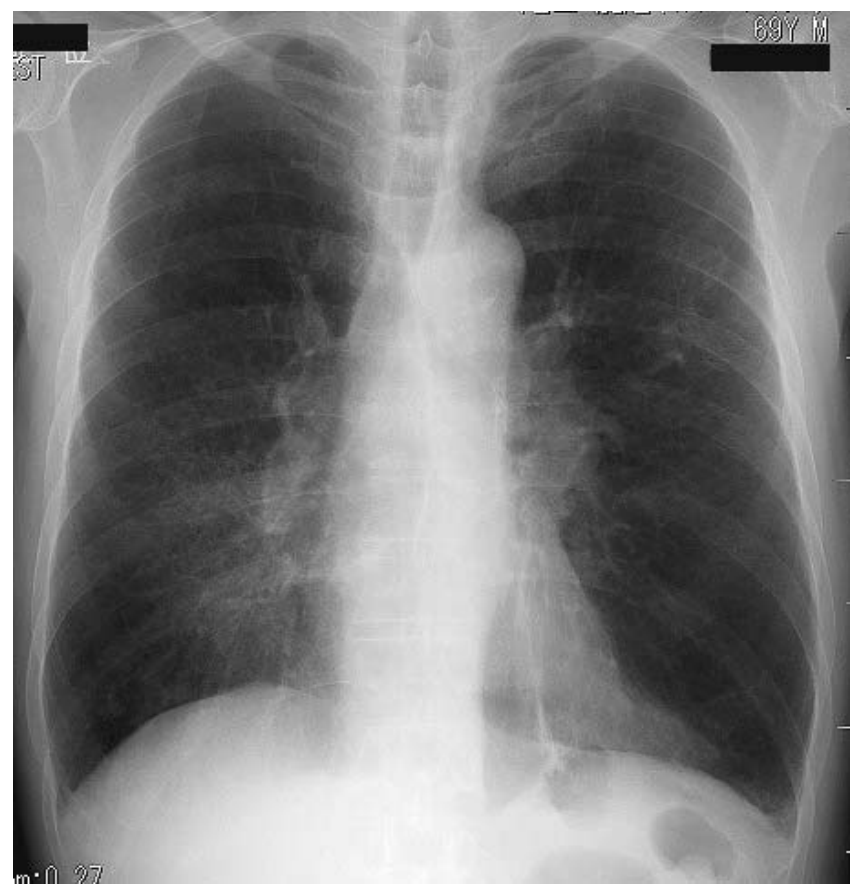

Figure 1. A chest roentgenogram showing bilateral hilar lymphadenopathy.
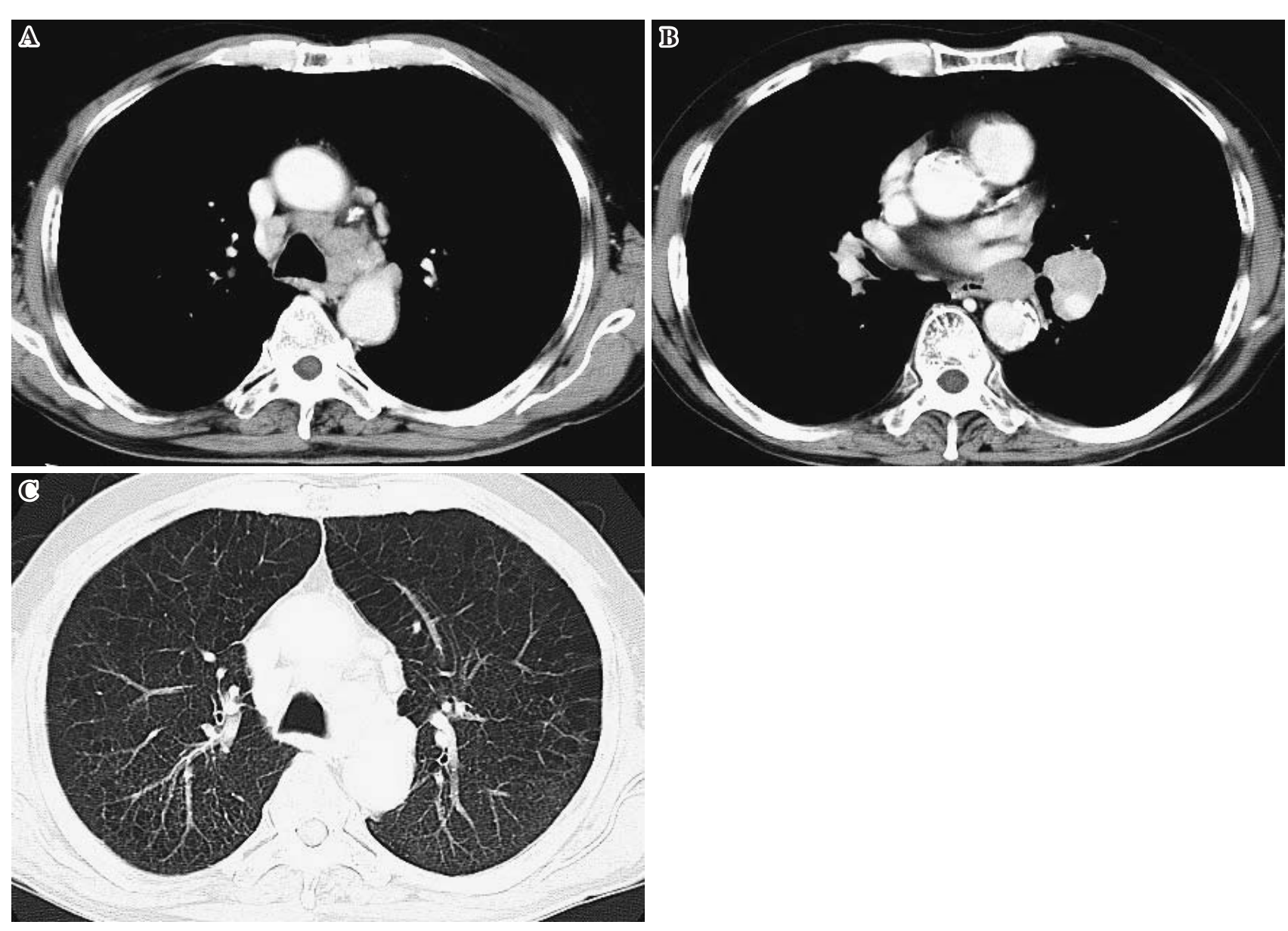

Figure 2. Chest computed tomography scan showing mediastinal and bilateral hilar lymph node enlargement, and extensive emphysema. follows: vital capacity (VC), $4.03 \mathrm{~L}(105.8 \%$ of the predicted value); forced expiratory volume at $1 \mathrm{~s}\left(\mathrm{FEV}_{1}\right), 1.29$ $\mathrm{L}$ (42.9\% of the predicted value); $\mathrm{FEV}_{1} / \mathrm{VC}$ ratio, $33.2 \%$; and the predicted lung diffusion capacity for carbon monoxide, $34.1 \%$. Hypoxemia (arterial oxygen tension, 54.8 torr) was observed.

A chest roentgenogram showed bilateral hilar lymphadenopathy (Fig. 1). A chest computed tomography (CT) scan showed mediastinal and bilateral hilar lymph node enlargement and extensive emphysema (Fig. 2). Further, the results of gallium-67 $\left({ }^{67} \mathrm{Ga}\right)$ scintigraphy showed ${ }^{67} \mathrm{Ga}$ uptake in both right and left hilar lymph nodes, mediastinal lymph nodes, and both lung fields (Fig. 3). Moreover, ${ }^{18} \mathrm{~F}-$ fluorodeoxyglucose (FDG) positron-emission tomography (PET) revealed intense FDG activity in the right and left hilar lymph nodes; mediastinal lymph nodes; and bones such as the ribs, breastbone, vertebral bodies, and pelvis (Fig. 4). Bronchoscopic examination revealed mild bronchial mucosal hypervascularity and an irregular protuberant lesion at the orifice of the left upper bronchus. Analysis of the bronchoalveolar lavage fluid (BALF) obtained from the right $\mathrm{B}^{5}$ revealed $95 \%$ macrophages, $3 \%$ lymphocytes, and $2 \%$ neutrophils and a CD4 to CD8 T lymphocyte ratio of 5.62 (CD4, $79.3 \%$; CD8, 14.1\%). Histological examination of broncho- 


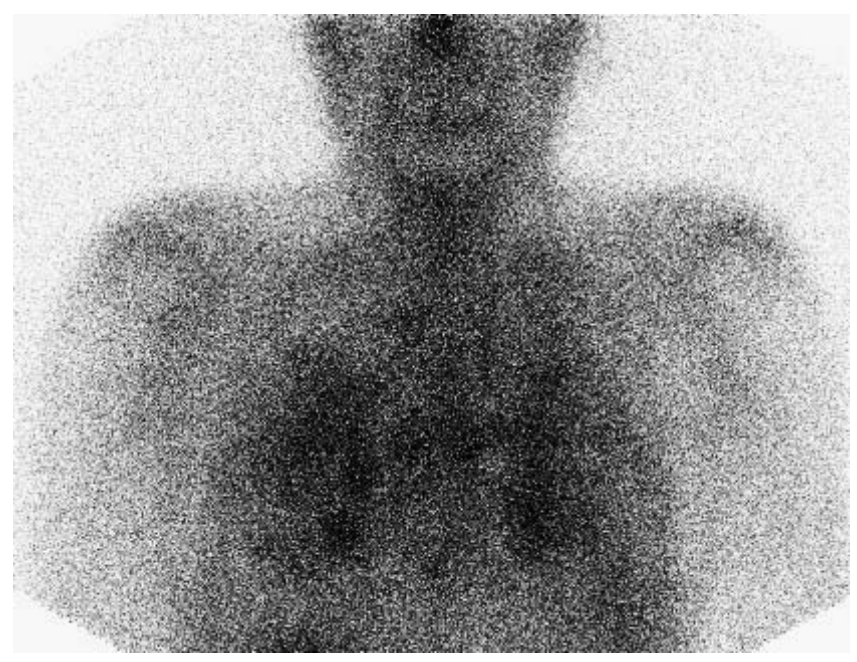

Figure 3. ${ }^{67}$ Ga scintigraphy showing uptake in the right and left hilar lymph nodes, mediastinal lymph nodes, and both lung fields.

scopic biopsy specimens obtained from the left $\mathrm{B}^{3}$ revealed noncaseating epithelioid cell granulomas containing giant cells; further, examination of the protuberant lesion at the orifice of the left upper bronchus revealed small cell lung cancer. However, examination of a single prepared slide did not reveal the simultaneous presence of small cell carcinoma and sarcoidosis. On the basis of the above findings, the patient was diagnosed with pulmonary sarcoidosis and small cell lung cancer (cT1aN2M1b, stage IV) (Fig. 5). Moreover, QuantiFERON TB-2G (Cellestis; South Melbourne, Australia) test, bacterial culture of bronchial lavage fluid, and histological examination of bronchoscopic biopsy specimens did not provide any evidence of Mycobacterium infection this patient. There was no evidence of extrapulmonary involvement of sarcoidosis, including the skin, eye and heart.

The patient received 4 courses of chemotherapy consisting of intravenous administration of carboplatin (area under the curve $=6$, day 1$)$ and etoposide $\left(100 \mathrm{mg} / \mathrm{m}^{2}\right.$, days $\left.1-3\right)$ but no steroid. After 1 course, the ACE level was normalized (20.3 U/L). After 4 courses, FDG activity was not detected in the bones; however, PET revealed slight FDG activity in the left hilar and mediastinal lymph nodes. In addition, the NSE level was within the normal limit, but the Pro-GRP level remained high, i.e., $128 \mathrm{pg} / \mathrm{mL}$. A repeat bronchoscopic examination revealed disappearance of the tumor cells. Analysis of the BALF obtained from the right $\mathrm{B}^{5}$ revealed $95 \%$ macrophages, $2 \%$ lymphocytes, and $3 \%$ neutrophils and a CD4/CD8 ratio of 2.83 (CD4, 68.8\%; CD8, 24.2\%). Histological examination of the bronchoscopic biopsy specimen obtained from the left $\mathrm{B}^{3}$ did not provide any evidence of noncaseating epithelioid cell granulomas. Because the ProGRP level tended to increase, the patient was subsequently administered 2 additional courses of chemotherapy of the same regimen. The ACE level remained within the normal range during the treatment period. However, the mediastinal and left hilar lymph nodes were clearly enlarged, as revealed by chest CT; this finding suggested cancer progression.

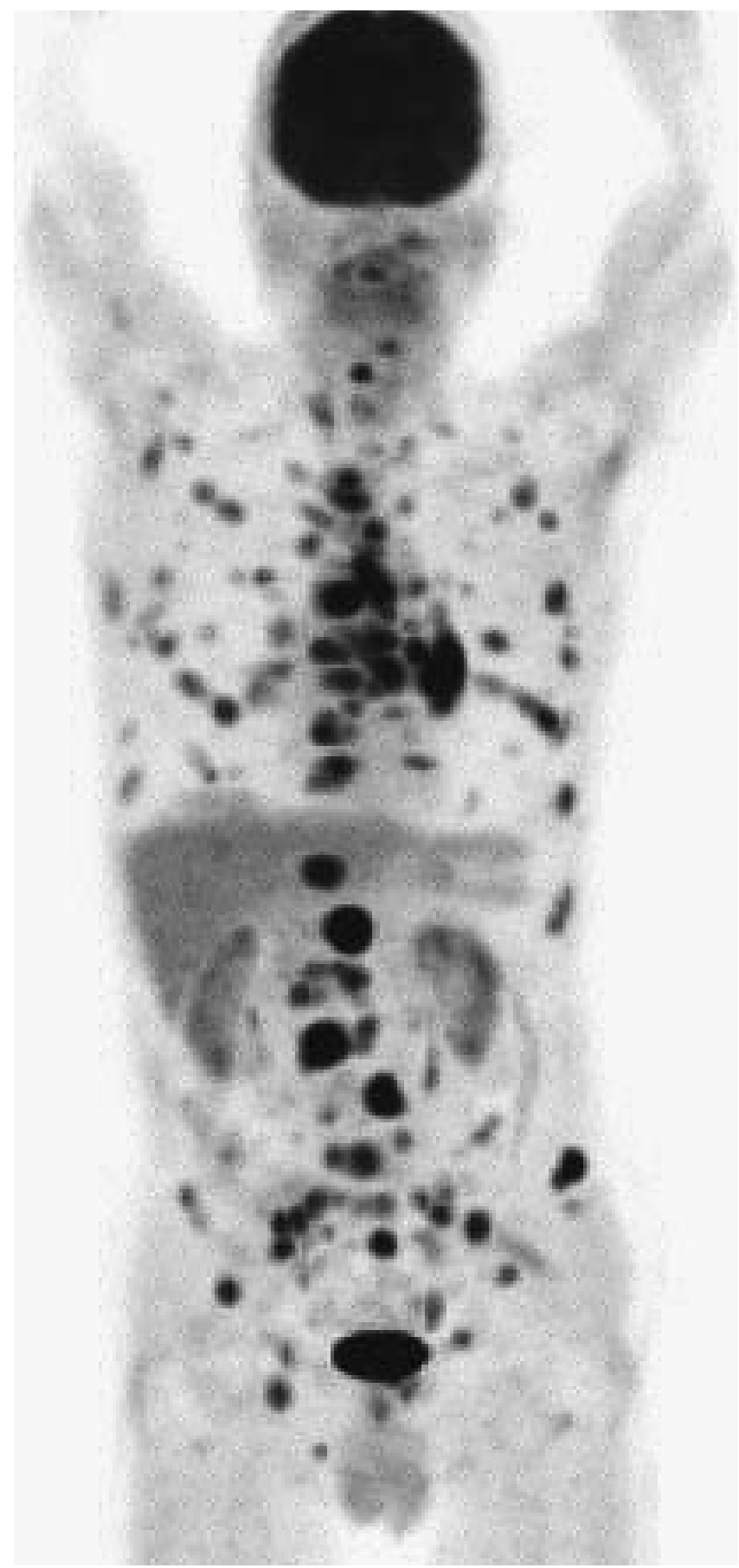

Figure 4. ${ }^{18}$ F-fluorodeoxyglucose (FDG) positron-emission tomography imaging showing intense FDG activity in the left hilar lymph nodes; mediastinal lymph nodes; bones such as ribs, breastbone, vertebral body bones, and pelvis.

Thereafter, treatment with irinotecan $\left(100 \mathrm{mg} / \mathrm{m}^{2}\right)$ as the second-line regimen was administered at weekly intervals, on days 1,8 and 15 of the treatment course.

\section{Discussion}

Localized epithelioid granulomas without any signs of systemic sarcoidosis rarely occur in the regional lymph nodes draining lung cancers or in the lung parenchyma surrounding the tumor. These changes were previously referred 


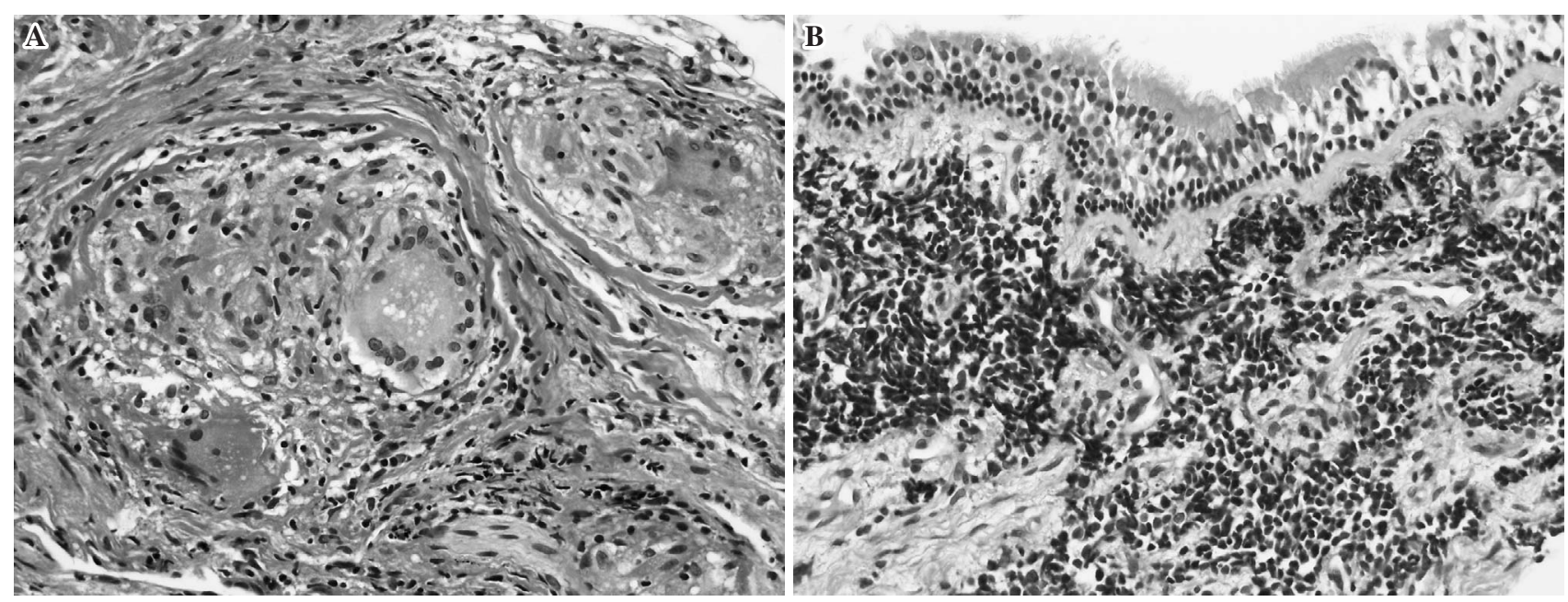

Figure 5. A) Histological examination of the bronchoscopic biopsy specimen taken from the left $B^{3}$ showing noncaseating epithelioid cell granulomas containing giant cells without any necrotic lesions. B) Microscopic findings of the bronchoscopic biopsy specimen taken from the protuberant lesion at the orifice of the left upper bronchus showing small cell lung cancer.

to as "sarcoid reaction" (1). The causes of sarcoid reactions remain to be clarified. Sarno et al reported that acceleration of immunoactivity might be related to the formation of sarcoid granulomas (2). Noncaseating epithelioid cell granulomas were detected in the pulmonary parenchyma in the left upper lobe, apart from tumor cells, in the case of this patient. These findings are not suggestive of a sarcoid reaction.

Sarcoidosis is a chronic granulomatous disease of unknown causes; it mainly involves the lungs but may also be associated with systemic manifestations (3). The incidence rate of sarcoidosis in Japan is 1.01 per 100,000 inhabitants (4). Pulmonary sarcoidosis and small cell lung cancer are commonly encountered diseases in the field of respiratory medicine, but their concomitant occurrence in a patient is rare. Brincker and Wilbek reported that 48 of 2,544 patients with respiratory sarcoidosis developed a malignant tumor during a period of 10 years; this incidence rate is higher than that among the general population (5). However, Romer carefully distinguished sarcoid reactions from sarcoidosis, and reassessed the data reported by Brincker and Wilbek; and showed that the incidence rate of cancer among patients with pulmonary sarcoidosis did not significantly differ from that among the general population (6). Moreover, Romer found that only 6 among 500 sarcoidosis patients who were followed up for 20 years developed cancer; this incidence rate is not higher than expected (7). Askling et al reported that 653 of 8,541 sarcoidosis patients developed a malignant tumor during a period of 32 years; the authors concluded that sarcoidosis patients appeared to be at an increased risk for lung cancer (8). Yamaguchi et al calculated the risk of lung cancer in a cohort of 1,411 sarcoidosis patients who were followed up for 3- years; they concluded that this cohort was at a significantly higher risk of death from lung cancer than was the general population (9). Owing to the contradictory reports, whether the incidence of lung cancer among sarcoidosis patients is high remains un- known. By 2008, 40 cases of concomitant occurrence of lung cancers and sarcoidosis in Japan were reported; these included 26 cases of adenocarcinoma, 10 cases of squamous cell carcinoma, and 4 cases of small cell lung cancer (10). In the case of the present patient, bronchoscopic examination was performed for further evaluation of bilateral hilar lymphadenopathy that was revealed by chest radiography, and the findings thus obtained were characteristic of sarcoidosis. Further, this patient was diagnosed with small cell lung cancer.

In the present patient, ${ }^{67} \mathrm{Ga}$ scintigraphy revealed bilateral hilar lymphadenopathy, which is indicative of sarcoidosis. Further, ${ }^{18}$ F-FDG PET revealed a more intense FDG activity in the left hilar and mediastinal lymph nodes than in the right hilar lymph nodes; this finding suggests that the left hilar and mediastinal lymph nodes contained small cell lung cancer. The frequency of osseous involvement of sarcoidosis varies, ranging from $1 \%$ to $13 \%$, depending on the race of the patient (11). The short tubular bones of the hands and feet are most frequently involved (12); however, in the present patient, bones such as the ribs, breastbone, vertebral bodies, and pelvis, were involved, as revealed by ${ }^{18} \mathrm{~F}-\mathrm{FDG}$ PET. These results suggest metastasis of small cell carcinoma in this case. Because of bone metastasis of small cell carcinoma, it was not necessary to examine the lymph node specimen to decide the treatment strategy.

The level of ACE, lymphocyte subsets in the BALF, CD4/ CD8- $T$ lymphocyte ratio in the BALF, and ${ }^{67} \mathrm{Ga}$ scintigraphy findings are assumed to be the markers of sarcoid activity (13). The present patient was diagnosed with active pulmonary sarcoidosis because of the high levels of ACE; high $\mathrm{CD} 4 / \mathrm{CD} 8$ ratio; and intense ${ }^{67} \mathrm{Ga}$ accumulation in the right and left hilar lymph nodes, mediastinal lymph nodes, and both lung fields. Treatment for small cell lung cancer normalized the ACE level and decreased the CD4/CD8 ratio; further, histological examination did not reveal the presence 
of noncaseating epithelioid-cell granulomas. Although the possibility of spontaneous remission of pulmonary sarcoidosis cannot be ruled out, we consider that chemotherapy for lung cancer improved sarcoidosis in the present patient.

Pulmonary sarcoidosis is usually a benign disease, and the patients do not require treatment; however, $20-25 \%$ of patients exhibit a permanent decrease in lung function, and $10 \%$ develop pulmonary fibrosis $(14,15)$. Although administration of systemic corticosteroids suppresses the symptoms of this disease in most patients, these drugs do not alter the natural course of the disease (16). In addition, some patients with an apparently active disease may require unacceptably high maintenance doses of corticosteroids to achieve or maintain improvement; consequently, these patients may experience the adverse effects of corticosteroids. For these patients and for patients who cannot be treated with corticosteroids owing to other reasons, alternative treatment with immunosuppressive agents such as methotrexate and azathioprine, has been used. Clinical improvement was reported in $60-80 \%$ of the patients treated with low-dose methotrexate $(10 \mathrm{mg}$ weekly) $(17,18)$ and in $50-80 \%$ of the patients treated with azathioprine $(19,20)$. Granulomatous inflammation associated with sarcoidosis is predominantly caused by T- helper 1 cells and is mediated by a complex network of lymphocytes, macrophages, and cytokines. Azathioprine exerts a strong suppressive effect on T- lymphocyte proliferation and activation (21). Low-dose methotrexate was shown to decrease the release of hydrogen peroxide and tumor necrosis factor by alveolar macrophages as well as reduce the number of lymphocytes and CD4/CD8 ratio in the BAL in the case of sarcoidosis patients (22); this finding suggests that methotrexate therapy has a direct effect on the macrophages and $\mathrm{T}$ lymphocytes at the sites of inflammation. Although the mechanism of action of carboplatin and etoposide in sarcoidosis patients remains unknown, the immunosuppressive activity of these drugs might be associated with clinical improvement. This is the first report that describes improvement of pulmonary sarcoidosis by chemotherapy for lung cancer.

In summary, we described the case of a patient with small cell lung cancer accompanied by pulmonary sarcoidosis. The coexistence of these 2 conditions is rare. Interestingly, anticancer agents that were administered for small cell lung cancer also improved pulmonary sarcoidosis.

\section{References}

1. Kamiyoshihara M, Hirai T, Kawashima O, Ishikawa S, Morishita Y. Sarcoid reactions in primary pulmonary carcinoma: Report of seven cases. Oncol Rep 5: 177-180, 1998.

2. Sarno M, Hasleton PS, Spiteri MA. Sarcoidosis. In: Spencer's Pathology of the Lung. 5th edition. Hasleton PS, Ed. McGraw-Hill, New York, 1996: 507-535.

3. Yamamoto M, Sharma OP, Hosoda Y. Special report-The 1991 descriptive definition of sarcoidosis. Sarcoidosis 9: 33-34, 1992.

4. Morimoto T, Azuma A, Abe S, et al. Epidemiology of sarcoidosis in Japan. Eur Respir J 31: 372-379, 2008.

5. Brincker $\mathrm{H}$, Wilbek $\mathrm{E}$. The incidence of malignant tumors in patients with respiratory sarcoidosis. Br J Cancer 29: 247-251, 1974.

6. Romer FK. Sarcoidosis and cancer-A critical view. In: Proceedings of the 8th International Conference on Sarcoidosis and other Granulomatous Diseases. Williams WJ, Davis BH, Eds. Alpha Omega Publishing Limited, London, 1980: 567-571.

7. Romer FK. Sarcoidosis and cancer. N Engl J Med 306: 1490, 1982.

8. Askling J, Grunewald J, Eklund A, Hillerdal G, Ekbom A. Increased risk for cancer following sarcoidosis. Am J Respir Crit Care Med 160: 1668-1672, 1999.

9. Yamaguchi M, Odaka M, Hosoda Y, et al. Excess death of lung cancer among sarcoidosis patients. Sarcoidosis 8: 51-55, 1991.

10. Yanagitani N, Kaira $K$, Ishizuka $T$, et al. A case of large cell neuroendocrine carinoma in a patient with sarcoidosis. Nihon Kokyuki Gakkai Zasshi 46: 574-577, 2008 (in Japanese).

11. James DG, Neville E, Siltzbach LE. A worldwide review of sarcoidosis. Ann NY Acad Sci 278: 321-334, 1976.

12. Wilcox A, Bharadwaj P, Sharma OP. Bone sarcoidosis. Curr Opin Rheumatol 12: 321-330, 2000.

13. Pozzi E, Ghio P, Albera C. Sarcoidosis activity markers. Sarcoidosis 5: 162-165, 1988.

14. Crystal RG, Bitterman PB, Rennard SI, Hance AJ, Keogh BA. Interstitial lung diseases of unknown cause. N Engl J Med 310: 235244, 1984.

15. Hillerdal G, Nou E, Osterman K, Schmekel B. Sarcoidosis: Epidemology and prognosis. Am Rev Respir Dis 130: 29-32, 1984.

16. Johns CH, Macgregor MI, Zachery JB, Ball WC. Extended experience in the long-term corticosteroid treatment of pulmonary sarcoidosis. Ann NY Acad Sci 278: 722-731, 1976.

17. Lower EE, Baughman RP. Prolonged use of methotrexate for sarcoidosis. Arch Intern Med 155: 846-851, 1995.

18. Baughman RP, Lower EE. A clinical approach to the use of methotrexate for sarcoidosis. Thorax 54: 742-746, 1999.

19. Lewis SJ, Ainslie GM, Bateman ED. Efficacy of azachioprine as second-line treatment in pulmonary sarcoidosis. Sarcoidosis Vasc Diffuse Lung Dis 16: 87-92, 1999.

20. Muller-Quernheim J, Kienast $\mathrm{K}$, Held $\mathrm{M}$, et al. Treatment of chronic sarcoidosis with an azachioprine/prednisolone regimen. Eur Respir J 14: 1117-1122, 1999.

21. Spina C. Azathioprine as an immunomodulating drug: clinical applications. Clin Immunol Allergy 4: 415-446, 1984.

22. Baughman RP, Lower EE. The effect of corticosteroid or methotrexate therapy on lung lymphocytes and macrophages in sarcoidosis. Am Rev Respir Dis 142: 1268-1271, 1990.

(C) 2010 The Japanese Society of Internal Medicine

http://www.naika.or.jp/imindex.html 